\title{
Readability and Suitability Assessment of university students Educational Materials in Preventing Smoking
}

\author{
Research Article
}

\section{Seyed Saeed Mazloomy Mahmoodabad ${ }^{1}$, Salime Zare Abdollahi²*, Mohammad Hasan Lotfi ${ }^{3}$, Seyed Mojtaba Yassini Ardakani ${ }^{4}$}

\author{
1. Professor, 2. PhD Student, Social Determinants of Health Research Center, \\ Department of Health Education and Promotion, School of Public Health, \\ 3. MD, PhD, Full Professor of Epidemiology, Department of Biostatistics and Epidemiology, Faculty of Health, \\ 4. MD, Research Center of Addiction and Behavioral Sciences, Yazd. \\ Shahid Sadoughi University of Medical Sciences, Yazd, Iran.
}

\begin{abstract}
Background: Educational materials are frequently used by health care providers to inform university students and young people about smoking and the health risks of smoking. However, little attention has been paid to the readability and suitability of these educational materials. Objectives: The study aimed to determine the readability and suitability of educational materials in preventing smoking for university students. Methods: Multiple instructional materials and books were used for the design and preparation of educational materials and were then tailored to the target group. Readability was measured by using the readability assessment of materials (RAM); and suitability was determined by the suitability assessment of materials (SAM) that considers characteristics such as content, graphics, layout/topography, and cultural appropriateness. Twenty reviewers, including 15 students and 5 health specialists scored the educational materials. Results: The mean readability score standard deviation(SD) of the educational materials was $8 \pm 1.6,9 \pm 1.5$ and $10 \pm 1.7$, for the booklet, the pamphlet of the skill of saying no, smoking pamphlet and quitting it, respectively, which were increased to $15 \pm 1.4,16 \pm 1.7$ and $17 \pm 0.8$, after tailoring the content. The average SAM scores before and after tailoring the content were $45 \%$ for the booklet, which was increased to $88 \%$ and $75 \%$ for the pamphlet of the skill of saying no, which was increased to $93 \%$ and $79 \%$ for the smoking pamphlet and quitting it, which was increased to $95 \%$. The increase in all scores was significant $(\mathrm{p}<$ 0.01).The final tailored educational material was rated "superior media" on the SAM ratings. Conclusions: Given that most of the printed materials are suitable for people with higher education levels, health providers are strongly advised to prepare simple and understandable education materials that may increase the likelihood of consumer perception and recall.
\end{abstract}

Key Words: Smoking, Students, Prevention, Readability, Suitability, Education Materials.

\section{Introduction}

Inadequate health literacy is an independent risk factor for poor health outcomes, including higher hospital admission rates (1), medication nonadherence (2), lower use of preventative services (3), and mortality $(4,5)$ Health literacy is defined as the degree to which individuals obtain, process, and understand basic health information and services needed to make appropriate decisions about their own health (6). Studies have shown that more than one third of adults have inadequate proficiency in health literacy tasks(7). Health literacy is essential to promote healthy individuals and communities (8). Low health literacy

* Corresponding Author:

Salime Zare Abdollahi

PhD Student, Social Determinants of Health Research Center, Department of Health Education and Promotion, School of Public Health, Shahid Sadoughi University of Medical Sciences, Yazd, Iran. Email Id: salimezare2319@gmail.com has a significant negative impact on both the health care system and individual health (9). Printed and web-based educational resources are often used to supplement and reinforce information provided by clinicians. New standards are being established to enhance the quality of patient education materials, such as recommendations to write educational materials at a sixth-grade reading level (10). Primary sources of health information are physicians and health professionals, but for reasons such as lack of time, large numbers of clients, high medical costs and poor communication skills, these specialists are not always able to meet patients' information needs $(8,11)$. Education can vary depending on the climatic conditions of each region and the temporal and spatial variables. The cultural and political conditions of the society have a great impact on the difference in educational content (12). The transmission of educational messages to learners is done through the use of educational media, which are an integral part of the educational process(13). One way to increase health literacy is to prepare appropriate educational material and tailor it to the target group (14). Much of this 
information is forgotten, when only oral information is provided. Thus health workers are encouraged to provide written educational material to people to reinforce and supplement information that has been provided orally (15). A small number of published evaluations are designed to assess the appropriateness of written health education materials(15). The benefits and importance of providing adolescences with education are widely confirmed. Educational material is frequently used by health workers and have advantages such as portability and consistency (16). The most common evaluations are Flash, Goning, Close, Suitability (SAM) and Readability (RAM) (17, 18). Readability and suitability are tools used to evaluate appropriateness of written information. Readability refers to the reading difficulty of a resource and uses word and sentence length to determine a score. Focusing on readability, however, is not enough for improving comprehension. Suitability measures how well the material can be understood and accepted by the reader(19, 20). Readability is the ease by which a reader can understand a written text. The SAM instrument is a validated method for evaluating written health-related educational materials. It is used to evaluate printed materials in terms of categories and factors known to enhance people's understanding of printed material(21). The instrument used to assess the appropriateness of written material are readability and suitability. Readability refers to the easiness or difficulty of reading an educational medium. However, readability alone is not enough for improving perception. Suitability offers a systematic method to objectively assess the suitability of health information materials for a particular audience in a short time (22). Smoking is mentioned as the first preventable cause of death in the world (23). The prevalence of smoking as a starting point for the use of other addictive substances is of particular importance (24). Smoking alone is the most important risk factor for preventable disease and an important cause of premature death (25). Cigarettes contain more than 4,000 carcinogenic and mutagenic toxins (26). It is estimated that 8.4 million people will die from smoking in 2020 (27). Currently, death in $87 \%$ of lung cancers and $82 \%$ of deaths due to obstructive pulmonary diseases are due to smoking. In addition, smoking has an effect on the cardiovascular system and $21 \%$ of deaths are due to coronary artery disease and $18 \%$ of deaths are due to heart disease(28). Smoking not only makes the smoker sick, but people who live around a smoker-risk encouraging the body to another person so that it is estimated that more than $30 \%$ of lung cancer(25). In the United States, a study on the effectiveness of smoking cessation programs showed that the most important reasons for starting smoking include the influence of friends, peer pressure, and other environmental factors. On the other hand, factors that prevent smoking cessation include lack of insurance coverage, lack of awareness of the existence of smoking cessation centers and lack of support groups(29). Another study in the United States found that smoking, habituation to smoking, relaxation, and enjoyment of smoking are among the most important reasons for continuing to smoke (30). Reasons to continue smoking are different from reasons to start smoking, because it is usually formed with motives such as curiosity, hobby, imitation or compliments of friends(31). Smoking is one of the important factors in adolescent and young adult population, causing numerous problems, such as cough and respiratory and cardiovascular diseases, as well as, physical compatibility and lung growth makes it difficult (32). The study of smoking among students is particularly important because smoking students useful indicator of smoking by young people and the other can play a role in increasing or reducing the prevalence of smoking in society (33). Despite this importance, little research has been done on smoking in Islamic countries, including Iran. In a study conducted in the United States, the prevalence of smoking was $26 \%$ in men and $3.6 \%$ in women(34). Given the tendency of some Youth to Smoking, it is necessary to use educational material to educate them about the harms of Smoking and its usage. For all target groups, written educational material for health issue will be useful, if it is understood by the recipient $(35,36)$ Though, little attention has been paid to the readability and suitability of these educational materials for University students.

\section{Objectives}

The aim of this study was to determine the readability and suitability of university students' educational materials in preventing smoking and quitting smoking.

\section{Methods \\ Study Design and Population}

This study was conducted in 2021 in Yazd, located in central Iran. The Participants enrolled in this study were 15 university students (5 students of each university including medical sciences, Yazd University and Azad University) and 5 health experts. In order to select 15 students, three universities that were previously randomly selected as the target group of the intervention were randomly selected and according to the prevalence of covid 19 and the absence of students in universities, after obtaining Their contact number and email, media evaluation checklist were emailed to them. In this study, the educational materials included for the booklet, the pamphlet of saying no, the pamphlet of smoking and quitting. In order to evaluate the appropriateness of the prepared educational materials, readable and appropriate tools were used.

The readability of the material was assessed by the "readability assessment of materials" (RAM) and suitability was accessed through the "suitability assessment materials" (SAM). Initially, the educational materials were evaluated technically by the experts. Then, according to their points of view, the necessary changes were made and the materials were tailored according to the target group. Tailored material was then returned to the target group and the suitability and readability were assessed again. 


\section{Readability Assessment of Materials (RAM)}

RAM assesses the difficulty of reading an educational medium in three parts, which are having a specialized content (range of scores 0-6), misspelling (range of scores 0-6), and typographical mistakes (range of scores $0-6$ ). The range of scores in media readability assessment is from 0 to 18 and the acceptable score is more than 10 (37).

\section{Suitability Assessment of Materials (SAM)}

Suitability was measured using the Suitability Assessment of Materials (SAM) created by Doak et al(38). The SAM is a systematic tool to assess printed health-related educational resources in a short amount of time. The SAM has been validated(39) and successfully used in prior studies of other printed health information $(40,41)$ The SAM consists of 6 evaluation criteria: content (e.g., "behavior information to help solve their problem"), literacy demand (e.g., "common, explicit words are used"), graphics (e.g., "simple, adultappropriate, line drawings/sketches are used"), layout and typography (e.g., "type size is at least 12 point, no ALL CAPS for long headers or running text"), learning stimulation and motivation (e.g., "complex topics are subdivided into small parts so that readers may experience small successes in understanding or problem solving"), and cultural appropriateness (e.g., "images and examples present the culture in positive ways").

Two readers were trained in the SAM scoring techniques. Each reviewer scored all study materials and was blinded to the source of the material. The mean SAM scores were used in the analysis. The SAM consists of 22 items grouped under six factors, namely content, literacy demands, graphics, layout and typography, learning stimulation and motivation, and cultural appropriateness. Each of the 22items is rated in terms of the degree to which it meets set criteria, on an ordinal scale of $0,1,2$, and not applicable, where $0=$ inadequate, $1=$ adequate, and $2=\operatorname{superior}(10)$. Scores are summed to yield an overall raw score for the material. This is converted to a percentage of the possible total score for that material, with $70 \%-100 \%$ being considered to be superior material, $40 \%-69 \%$ adequate material, and $0 \%-39 \%$ not suitable material $(42,43)$.

\section{Statistical Analysis}

The Kolmogorov-Smirnov (KS) test was used to check the normality of quantitative variables and showed that the data had a normal distribution. The collected data were analyzed by SPSS software version 16. Descriptive statistics were reported for all variables. The mean score of SAM and RAM before and after tailoring was compared using paired t-tests. The level of significance in the tests was considered less than 0.05.

\section{Results}

Of the 20 participants in the study, 15 in this study were 15 university students (5 students from each university including medical sciences, Yazd University and Azad University). Were selected, randomly selected the mean age of students was $21.87 \pm 5.09$. Participants were $53 \%$ girls and $46.7 \%$ boys, and 5 students were randomly selected from each university. Also, 5 health specialists with $\mathrm{PhD}$ degrees were selected (of which 3 were health education specialists, 1 was an epidemiologist and 1 was a health information management specialist). Their mean age was $45.6 \pm$ 9.07. (Table 1)

Table 1. Demographic characteristics of participants

\begin{tabular}{|c|c|c|c|c|c|}
\hline \multicolumn{3}{|c|}{ Variable } & \multirow{2}{*}{$\begin{array}{c}\mathbf{N} \\
15\end{array}$} & \multirow{2}{*}{$\begin{array}{l}\text { Mean } \\
21.87\end{array}$} & \multirow{2}{*}{$\begin{array}{l}\text { S.D } \\
5.09\end{array}$} \\
\hline \multirow{12}{*}{ Students } & Age & & & & \\
\hline & \multirow{2}{*}{ Gender } & Girl & 8 & 53.3 & \\
\hline & & Boy & 7 & 46.7 & \\
\hline & Marital status & Single & 10 & 66.7 & \\
\hline & \multirow{5}{*}{ University } & Married & 3 & 20.0 & \\
\hline & & divorced & 2 & 13.3 & \\
\hline & & Medical Sciences university & 5 & 33.3 & \\
\hline & & Yazd university & 5 & 33.3 & \\
\hline & & Islamic Azad university & 5 & 33.3 & \\
\hline & \multirow[t]{3}{*}{ Field of Study } & Medical & 5 & 33.3 & \\
\hline & & Nursing & 5 & 33.3 & \\
\hline & & Physics & 5 & 33.3 & \\
\hline \multirow{7}{*}{$\begin{array}{l}\text { Health } \\
\text { specialist }\end{array}$} & \multirow{3}{*}{ Gender } & Age & 5 & 45.6 & 9.07 \\
\hline & & Female & 1 & 20 & \\
\hline & & Man & 4 & 80 & \\
\hline & Education rate & $\mathrm{PhD}$ & 5 & 100 & \\
\hline & Field of Study & Health Education & 3 & 60 & \\
\hline & & Epidemiology & 1 & 20 & \\
\hline & & Health Information Management & 1 & 20 & \\
\hline
\end{tabular}


Salime Zare Abdollahi et.al., Readability and Suitability Assessment of university students Educational Materials in Preventing Smoking

The mean readability score standard deviation (SD) of the educational materials were $8 \pm 1.6,9 \pm 1.5$ and $10 \pm 1.7$, for the booklet, the pamphlet of the skill of saying no, smoking pamphlet and quitting it, which were increased to $15 \pm 1.4,16 \pm 1.7$ and $17 \pm 0.8$, after tailoring the content. (Table 2)

Table 2. Mean Score of the "Readability Assessment of Materials" Before and After Tailoring

\section{Readability \\ Score}

Before

After
Booklet

$8 \pm 1.6$

$15 \pm 1.4$
Materials

The pamphlet of the skill of saying no Smoking pamphlet and quitting it

$9 \pm 1.5$
$16 \pm 1.7$

$10 \pm 1.7$

$17 \pm 0.8$

The average SAM scores before and after tailoring the content were $45 \%$ for the booklet, which was increased to $88 \%$. The increase in score was significant $(\mathrm{p}<0.001)$. Those findings showed the final educational material was "superior media" on the SAM ratings (Table 3).

Table 3. Results of the Assessment the booklet SAM Score Check List Before and After Tailoring SAM Item and Description Score Before Tailoring Score After Tailoring p-value

\section{1- Content}
a. Purpose is evident
b. Content about behavior
c. Scope is limited
d. Summary or review included

\section{2- Literacy demand}

\begin{tabular}{|c|c|}
\hline $1.00 \pm 0.55$ & $2 \pm 00$ \\
\hline $0.70 \pm 0.65$ & $2 \pm 0.0$ \\
\hline $0.80 \pm 0.61$ & $2 \pm 0.0$ \\
\hline & $1.60 \pm 0.50$ \\
\hline & \\
\hline $0.65 \pm 0.48$ & $1.65 \pm 0.48$ \\
\hline $0.60 \pm 0.61$ & $1.65 \pm 0.48$ \\
\hline $1.00 \pm 0.55$ & $1.70 \pm 0.47$ \\
\hline $1.00 \pm 0.55$ & $1.80 \pm 0.45$ \\
\hline & $1.50 \pm 0.51$ \\
\hline
\end{tabular}

\section{3- Graphics}
a. Reading grade level
b. Writing style, active voice
c. Vocabulary uses common words
d. Context is given first
e. Learning aids via "road signs"
a. Cover graphic shows purpose
b. Type of graphics
c. Relevance of illustrations
d. List, tables, etc. explained
e. Captions used for graphics

4- Layout and typography
a. Layout factors
b. Typography
c. Subheads (chunking) used

5-Learning stimulation, motivation

\begin{tabular}{|c|c|}
\hline $1.00 \pm 0.56$ & $2 \pm 0.0$ \\
\hline $1.00 \pm 0.71$ & $2 \pm 0.0$ \\
\hline $1.00 \pm 0.64$ & $1.50 \pm 0.52$ \\
\hline $1.00 \pm 0.72$ & $1.50 \pm 0.52$ \\
\hline & $2 \pm 0.0$ \\
\hline
\end{tabular}

$<0.001$
a. Interaction used
b. Behaviors are modeled and specific
c. Motivation-self-efficacy

\section{6- Cultural appropriateness}

a. Match in logic, language, experience

b. Cultural image and examples

Total score earned by SAM

Percentage points earned by SAM

\begin{tabular}{|l|l|}
\hline $1.00 \pm 0.55$ & $1.70 \pm 0.50$ \\
\hline $0.80 \pm 0.44$ & $1.60 \pm 0.51$ \\
\hline $0.90 \pm 0.48$ & $1.80 \pm 0.36$ \\
\cline { 2 - 2 } & \\
\hline $1.00 \pm 0.60$ & $1.60 \pm 0.50$ \\
\hline $1.00 \pm 0.60$ & $1.80 \pm 0.36$ \\
\hline \multirow{2}{*}{$1.20 \pm 0.58$} & $1.80 \pm 0.44$ \\
\hline
\end{tabular}

The average SAM score for the pamphlet of the skill of saying no was $75 \%$, which significantly increased to $93 \%$ after tailoring the content. The increase in score was significant $(\mathrm{p}<0.01)$. Those findings showed the final educational material was "superior media" on the SAM ratings (Table 4). 
Table 4. Results of the Assessment the pamphlet of the skill of saying no SAM Score Check List Before and After Tailoring

\section{SAM Item and Description}

\section{Score Before Tailoring}

\section{Score After \\ Tailoring}

p-value

\section{1- Content}

\begin{tabular}{|c|c|c|}
\hline \\
\hline a. Purpose is evident & $2 \pm 0.0$ & $2 \pm 0.0$ \\
\hline b. Content about behavior & $2 \pm 0.0$ & $2 \pm 0.0$ \\
\hline c. Scope is limited & $2 \pm 0.0$ & $2 \pm 0.0$ \\
\hline d. Summary or review included & \multirow{2}{*}{$2 \pm 0.0$} & $2 \pm 0.0$ \\
\hline \multicolumn{2}{|l|}{ 2- Literacy demand } & \\
\hline a. Reading grade level & $2 \pm 0.0$ & $2 \pm 0.0$ \\
\hline b. Writing style, active voice & $2 \pm 0.0$ & $2 \pm 0.0$ \\
\hline c. Vocabulary uses common words & $2 \pm 0.0$ & $2 \pm 0.0$ \\
\hline d. Context is given first & $0.50 \pm 0.55$ & $2 \pm 0.0$ \\
\hline e. Learning aids via "road signs" & \multirow{2}{*}{$1.00 \pm 0.72$} & $2 \pm 0.0$ \\
\hline 3- Graphics & & \\
\hline a. Cover graphic shows purpose & $0.0 \pm 0.0$ & $1.50 \pm 0.42$ \\
\hline b. Type of graphics & $1.00 \pm 0.60$ & $2 \pm 0.0$ \\
\hline c. Relevance of illustrations & $2 \pm 0.0$ & $2 \pm 0.0$ \\
\hline d. List, tables, etc. explained & $0.0 \pm 0$ & $1.00 \pm 0.40$ \\
\hline e. Captions used for graphics & \multirow{2}{*}{$2 \pm 0.0$} & $2 \pm 0.0$ \\
\hline 4- Layout and typography & & \\
\hline a. Layout factors & $1.00 \pm 0.60$ & $2 \pm 0.0$ \\
\hline b. Typography & $1.00 \pm 0.60$ & $1.5 \pm 0.45$ \\
\hline c. Subheads (chunking) used & \multirow{2}{*}{$2 \pm 0.0$} & $2 \pm 0.0$ \\
\hline 5- Learning stimulation, motivation & & \\
\hline a. Interaction used & $2 \pm 0.0$ & $2 \pm 0.0$ \\
\hline b. Behaviors are modeled and specific & $1.00 \pm 0.60$ & $1.50 \pm 0.42$ \\
\hline c. Motivation-self-efficacy & \multirow{2}{*}{$1.50 \pm 0.70$} & $2 \pm 0.0$ \\
\hline 6- Cultural appropriateness & & \\
\hline a. Match in logic, language, experience & $2 \pm 0.0$ & $2 \pm 0.0$ \\
\hline b. Cultural image and examples & $2 \pm 0.0$ & $2 \pm 0.0$ \\
\hline Total score earned by SAM & 33 & 41 \\
\hline Percentage points earned by SAM & 75 & 93 \\
\hline
\end{tabular}

The average SAM score for the smoking pamphlet and quitting it was $79 \%$, which significantly increased to $95 \%$ after tailoring the content .The increase in score was significant $(p<0.001)$. Those findings showed the final educational material was "superior media" on the SAM ratings (Table 5).

Table 5: Results of the Assessment the smoking pamphlet and quitting it SAM Score Check List Before and After Tailoring

\section{SAM Item and Description}

\begin{tabular}{|c|c|}
\hline $\begin{array}{c}\text { Score Before } \\
\text { the Tailoring }\end{array}$ & $\begin{array}{c}\text { Score After the } \\
\text { Tailoring }\end{array}$ \\
\hline $2 \pm 0.0$ & $2 \pm 0.0$ \\
\hline $1.50 \pm 0.32$ & $2 \pm 0.0$ \\
\hline $2 \pm 0.0$ & $2 \pm 0.0$ \\
\hline $1.00 \pm 0.25$ & $1.20 \pm 0.53$ \\
\hline $1.50 \pm 0.78$ & $2 \pm 0.0$ \\
\hline $1.00 \pm 0.65$ & $1.80 \pm 0.34$ \\
\hline $1.50 \pm 0.65$ & $2 \pm 0.0$ \\
\hline $1.00 \pm 0.60$ & $2 \pm 0.0$ \\
\hline $1.00 \pm 0.80$ & $2 \pm 0.0$ \\
\hline $1.50 \pm 0.60$ & $2 \pm 0.0$ \\
\hline $2 \pm 0.0$ & $2 \pm 0.0$ \\
\hline $2 \pm 0.0$ & $2 \pm 0.0$ \\
\hline
\end{tabular}

P Value

Content -1
a. Purpose is evident
b. Content about behavior
c. Scope is limited
d. Summary or review included

2- Literacy demand
a. Reading grade level
b. Writing style, active voice
c. Vocabulary uses common words
d. Context is given first
e. Learning aids via "road signs

\section{3- Graphics}

a. Cover graphic shows purpose

b. Type of graphics

c. Relevance of illustrations

$2 \pm 0.0$

$2 \pm 0.0$ 
Salime Zare Abdollahi et.al., Readability and Suitability Assessment of university students Educational Materials in Preventing Smoking

\begin{tabular}{|c|c|c|}
\hline d. List, tables, etc. explained & $1.00 \pm 0.75$ & $2 \pm 0.0$ \\
\hline e. Captions used for graphics & $2 \pm 0.0$ & $2 \pm 0.0$ \\
\hline \begin{tabular}{|c|} 
4- Layout and typography \\
a. Layout factors
\end{tabular} b. Typography & $2 \pm 0.0$ & $2 \pm 0.0$ \\
\hline c. Subheads (chunking) used & $1.50 \pm 0.65$ & $2 \pm 0.0$ \\
\hline 5- Learning stimulation, motivation & $1.00 \pm 0.55$ & $2 \pm 0.0$ \\
\hline a. Interaction used & $2 \pm 0.0$ & $2 \pm 0.0$ \\
\hline b. Behaviors are modeled and specific & $2 \pm 0.0$ & $2 \pm 0.0$ \\
\hline c. Motivation-self-efficacy & $1.50 \pm 0.72$ & $2 \pm 0.0$ \\
\hline 6- Cultural appropriateness & $2 \pm 0.0$ & $2 \pm 0.0$ \\
\hline a. Match in logic, language, experience & $2 \pm 0.0$ & $2 \pm 0.0$ \\
\hline Total score earned by SAM & $\mathbf{3 5}$ & $\mathbf{4 2}$ \\
\hline Percentage points earned by SAM & $\mathbf{7 9}$ & $\mathbf{9 5}$ \\
\hline
\end{tabular}

\section{Discussion}

Educators must choose the best and most effective type of media and educational methods that suit the needs and level of learners. Standard training material is one of the important factors in better and more effective training. The present study aimed to determine the readability and suitability of some of some prepared university students educational materials in smoking prevention.

In this study, the fit analysis showed that Suitability Assessment of Materials (SAM) in the skill pamphlet of saying no, smoking pamphlet and quitting, was in the excellent range before sewing and reached a high range after sewing, but the booklet was in the appropriate range before sewing and after sewing It was in the range of excellent media. This finding is consistent with the results of a study by Sadeghi et al. In Iran on the readability and appropriateness of adolescents' educational materials in preventing hookah smoking(44). Also in the study of Morouti et al. In Iran on Readability and Suitability Assessment of Educational Materials in Promoting the Quality of Life for Postmenopausal Women (45). Hoffmann et al.'s study in Australia about assessing the suitability of written stroke material was in line with our findings and showed printed material enhance people's understanding (15). Finnie et al. in a systematic review showed only two of the seven Cancer Education Print and Web-based material were suitable(46). This finding is consistent with results from the Okuhara et al. study in Japan about the educational material on cancer screening announcements in municipal newspapers(47) and Rhee et al. in the USA about the educational material about rheumatic diseases(22). also in Weintraub et al study titled an evaluation of the written education materials for patients with prostate cancer, the mean overall SAM rating was "adequate." (41).

Readability Assessment of Materials (RAM), Before and after sewing, smoking pamphlet and quitting it ,was in the acceptable range, while the booklet and the skill pamphlet of saying no, before sewing was not in the acceptable range, which increased after sewing; In these studies, education material was written at a high readability level and had an effect on the target
group.However, the results of Walsh and Volsko in the USA about the readability assessment of internet-based consumer health information(48). Is not consistent with this study and the educational material assessed in their study did not have proper readability and were in the category of "difficult" media. The mean readability level of materials in Eames et al. study titled The Suitability of Written Education Materials for Stroke Survivors and Their Carers was (grade 9) higher than participants' mean reading ability (grade 7-8) (49). while the mean score of readability of the smoking pamphlet and quitting it, in this study was acceptable $(>10)$ that is not consistent with Eames's study but This finding is consistent with results from the Sadeghi et al study(44). Also This finding is consistent in the study of Morovati et al(45). Finnie et al. in a systematic review showed only two of the seven Cancer Education Print and Web-based materials were suitable(46).

Thus modifying written educational material and tailoring them according to the target audience is important for facilitating learning and recall of the information. Readability refers to the ease of comprehension of printed material with respect to its writing style (50).and suitability assessment can be used to evaluate printed materials against factors known to enhance people's understanding of printed materials(43).

A limitation of this study was the small sample of participants $(n=20)$ which may not be representative of All university students and their problems. Proper planning should be done for the production and distribution of educational media in accordance with the readability and suitability standards. Also, health educators who prepare education materials should be trained for this goal.

\section{Conclusion}

The content and design of written education material should be evaluated before using them the value of the SAM is that it can be used to identify specific elements that should be modified before education materials provided to the target group. The findings indicated that the printed materials were wellmatched after evaluation by the RAM and the SAM 
checklist and they were in accordance with the characteristics of the university students Compliance with these recommendations may increase the likelihood of consumer comprehension.

\section{Ethics approval and consent to participate}

Ethical approval for this study has been obtained by the ethics committee affiliated with Shahid Sadoughi University of Medical Sciences, Yazd, Iran (IR.SSU.SPH.REC.1399.174). Registration of this randomized control trial has been completed with the Iranian Registry of Clinical Trials, IRCT20200908048656N1.

\section{Acknowledgments}

The authors would like to thank the research deputy of Shahid Sadoughi University of Medical Sciences, which financially supported this research and all of the individuals who participated in this study.

\section{Conflict of Interests}

The authors declare that they have no conflict of interest.

\section{Funding/Support}

Research deputy of Shahid Sadoughi University of Medical Sciences.

\section{Patient Consent}

The aim of the study was explained to the participants and written informed consent was obtained from the participants

\section{References}

1. Baker DW GJ, Williams MV, Scott T, Parker RM, Green D, et al. . Functional health literacy and the risk of hospital admission among Medicare managed care enrollees. . Am J Public Health 2002;92:1278 - 83

2. Lindquist LA GL, Fleisher J, Jain N, Friesema E, Baker DW. Relationship of health literacy to intentional and uninten tional non-adherence of hospital discharge medications. . J Gen Intern Med 2012;27:173-8

3. Scott TL GJ, Williams MV, Baker DW. . Health literacy and preventive health care use among Medicare en rollees in a managed care organization. . Med Care 2002;40: 395-404

4. Baker DW WM, Feinglass J, Thompson JA, Gazmararian JA, Huang J. . Health literacy and mortality among elderly persons. . Arch Intern Med 2007;167:1503-9

5. Pincus T KJ, Sokka T, Krishnan E, Callahan LF. Patient questionnaires and formal education level as prospective pre dictors of mortality over 10 years in $97 \%$ of 1416 patients with rheumatoid arthritis from 15 United States private practices. J Rheumatol 2004;31:229-34

6. U.S. Department of Health and Human Services. Office of Disease Prevention and Health Promotion. National action plan to improve health literacy. .
2010 . URL:; http://www. health.gov/ communication/hlactionplan/pdf/Health_Literacy_ Action_Plan.pdf. .

7. Kutner M GE, Jin Y, Paulsen C. . The health literacy of America's adults: results from the 2003 National Assess ment of Adult Literacy. . URL: http://ncesedgov/ pubs2006/2006483pdf 8 Doak CC, Doak L, Root JH Teaching patients with low literacy skills 2nd ed. 2006;. Philadelphia: JB Lippincott Company; 1996.

8. Nutbeam D. Health promotion glossary. Health promotion international. 1998;13(4):349-64.

9. Oates DJ, Paasche-Orlow MK. CLINICIAN UPDATE CLINICIAN UPDATE. Circulation. 2009;119:1049-51.

10. Doak CC, Doak LG, Root JH. Teaching patients with low literacy skills. AJN The American Journal of Nursing. 1996;96(12):16M.

11. Kutner M, Greenburg E, Jin Y, Paulsen C. The Health Literacy of America's Adults: Results from the 2003 National Assessment of Adult Literacy. NCES 2006-483. National Center for Education Statistics. 2006.

12. Farrokhi M, Teimouri S, Naghipour D. Study on Adaptation of Educational Contents and Educational Needs in Public Health School of Guilan University of Medical Sciences. Research in Medical Education. 2010;2(1):42-8.

13. Baghiyani moghadam M SrM, Rahaei Z, Nadrian $\mathrm{H}$, Mohammadi M, Fallahi A, et al. Educational technology. . Tehran: Asaresobhan;. 2013. p. 58. [In Persian].

14. Kreuter MW, Wray RJ. Tailored and targeted health communication: strategies for enhancing information relevance. American journal of health behavior. 2003;27(1):S227-S32.

15. Hoffmann T, Ladner Y. Assessing the suitability of written stroke materials: An evaluation of the interrater reliability of the suitability assessment of materials (SAM) checklist. Topics in stroke rehabilitation. 2012;19(5):417-22.

16. McKenna K, Tooth L. Client education: a partnership approach for health practitioners: UNSW Press; 2006.

17. GHADERI MME, SOBHANI NM. Validation methods to measure textbooks readability. 2016.

18. Fazlullahi S, Maleki Tawana M. Methodology of Content analysis with an Approach to Techniques for Readability Assessment and Coefficient of Text Engagement. Pazhuhesh. 2010;2(1):71-94.

19. Schumacher HR. Patient education: How can we improve it and evaluate the effects? : LWW; 2011.

20. Hearth-Holmes M, Murphy PW, Davis TC, Nandy I, Elder CG, Broadwell LH, et al. Literacy in patients with a chronic disease: systemic lupus erythematosus and the reading level of patient education materials. The Journal of rheumatology. 1997;24(12):2335-9.

21. Garnweidner-Holme LM, Dolvik S, Frisvold C, Mosdøl A. Suitability assessment of printed dietary guidelines for pregnant women and parents of infants and toddlers from 7 European countries. 
Journal of nutrition education and behavior. 2016;48(2):146-51. e1.

22. Rhee RL, Von Feldt JM, Schumacher HR, Merkel PA. Readability and suitability assessment of patient education materials in rheumatic diseases. Arthritis care \& research. 2013;65(10):1702-6.

23. Hays JT, Ebbert JO. Bupropion for the treatment of tobacco dependence. CNS drugs. 2003;17(2):71-83.

24. Maarefvand M, Jamali T, Hosseinzadeh S. The Effectiveness of Smoking Prevention Intervention with Peer Education Approach on Labor Children's Attitude Toward Smoking. Quarterly Journal of Social Work. 2016;4(4):17-28.

25. American College of Chest Physicians ATS, Asian Pacific Society of Respirology, Canadian Thoracic Society, European Respiratory Society, International Union Against Tuberculosis, Disease L. Smoking and health: A physician's responsibility A statement of the Joint Committee on Smoking and Health. Respirology. 1996;1(1):73-7.

26. Rennard SI. Cigarette smoke in research. American journal of respiratory cell and molecular biology. 2004;31(5):479-80.

27. Murray CJ, Lopez AD. Alternative projections of mortality and disability by cause 1990-2020: Global Burden of Disease Study. The lancet. 1997;349(9064):1498-504.

28. OotUS. G. Reducing the health consequences of smoking :25 years of progress Atlanta GA. : Office on Smoking and Health ,. 1989.

29. Giuliani KK, Mire OA, Jama S, DuBois DK, Pryce $\mathrm{D}$, Fahia $\mathrm{S}$, et al. Tobacco use and cessation among Somalis in Minnesota. American journal of preventive medicine. 2008;35(6):S457-S62.

30. 30. Baker T FB, Smith S, Fiore M, Meyer G, Redmond L, et al. . Why do People Smoke 2002.

31. Gholamreza Heydari MH, Mahmoud Yoosefi Fard, Ali Ramezankhani, Mohammadreza Masjedi. . Does smoking cessation result depend on smoking reason?. . Payesh. 2010;; 9 (4) :363-369(URL: http://payeshjournal.ir/article-1-551-fa.html).

32. Memon A, Moody PM, Sugathan TN, El-Gerges N, Al-Bustan M, Al-Shatti A, et al. Epidemiology of smoking among Kuwaiti adults: prevalence, characteristics, and attitudes. Bulletin of the World Health Organization. 2000;78:1306-15.

33. Jamshid A, Khalili H, Jooybar R, Namazi N, Mohammadagaei P. Prevalence of cigarette smoking in Iran. Psychological reports. 2001;89(2):339-41.

34. Rigotti NA, Lee JE, Wechsler H. US college students' use of tobacco products: results of a national survey. Jama. 2000;284(6):699-705.

35. Michie S vSM, West R. . The behaviour change wheel: A new method for characterising and designing behaviour change interventions. . I m ple me n t Sci . $2011 ; ; 6: 42$. d o i : 10.1186/1748-5908-6-42. [PubMed: 21513547]. [PubMed Central: PMC3096582]. .
36. Doak C, Doak L, Root J. Suitability assessment of materials. SAM, Washington, DC. 1994.

37. Gold J, Aitken C, Dixon H, Lim M, Gouillou M, Spelman $\mathrm{T}$, et al. A randomised controlled trial using mobile advertising to promote safer sex and sun safety to young people. Health Education Research. 2011;26(5):782-94.

38. Doak CC, Doak LG, Root JH. Teaching patients with low literacy skills. 1985.

39. Doak C, Doak L, Root J. Suitability assessment of materials. Washington, DC: SAM. 1994.

40. Vallance JK, Taylor LM, Lavallee C. Suitability and readability assessment of educational print resources related to physical activity: Implications and recommendations for practice. Patient education and counseling. 2008;72(2):342-9.

41. Weintraub D, Maliski SL, Fink A, Choe S, Litwin MS. Suitability of prostate cancer education materials: applying a standardized assessment tool to currently available materials. Patient education and counseling. 2004;55(2):275-80.

42. Lewis SL. Implementing the Suitability Assessment of Materials (SAM) to Improve Health Literacy at a Rural Community Health Center. 2014.

43. Doak CC, Doak LG, Root JH. Teaching patients with low literacy skills. Teaching patients with low literacy skills1985. p. 171-.

44. Sadeghi R, Mazloomy Mahmoodabad SS, Fallahzadeh H, Rezaeian M, Bidaki R, Khanjani N. Readability and suitability assessment of adolescent education material in preventing hookah smoking. International Journal of High Risk Behaviors and Addiction. 2019;8(1).

45. Morowatisharifabad MA, Yoshany N, Sharma M, Bahri N, Jambarsang S. Readability and suitability assessment of educational materials in promoting the quality of life for postmenopausal women. Przeglad Menopauzalny $=$ Menopause Review. 2020;19(2):80.

46. Finnie RK, Felder TM, Linder SK, Mullen PD. Beyond reading level: a systematic review of the suitability of cancer education print and Web-based materials. Journal of Cancer Education. 2010;25(4):497-505.

47. Okuhara T, Ishikawa H, Okada H, Kiuchi T. Readability, suitability and health content assessment of cancer screening announcements in municipal newspapers in Japan. Asian Pacific Journal of Cancer Prevention. 2015;16(15):6719-27.

48. Walsh TM, Volsko TA. Readability assessment of internet-based consumer health information. Respiratory care. 2008;53(10):1310-5.

49. Eames S, McKenna K, Worrall L, Read S. The suitability of written education materials for stroke survivors and their carers. Topics in Stroke Rehabilitation. 2003;10(3):70-83.

50. Buxton T. Effective ways to improve health education materials. Journal of Health Education. 1999;30(1):47-61. 